\title{
QUALITY OF LIFE IS SEVERELY COMPROMISED IN ADULT PATIENTS WITH ATOPIC DERMATITIS IN BRAZIL, ESPECIALLY DUE TO MENTAL COMPONENTS
}

\author{
Silvana Coghi ${ }^{1}$, Maria Cecilia Bortoletto ${ }^{1}$, S.A.P. Sampaio ${ }^{1}$, Heitor Franco de \\ Andrade Junior ${ }^{2}$, Valeria Aoki ${ }^{1}$
}

Coghi S, Bortoletto MC, Sampaio SAP, Andrade Junior HF, Aoki V. Quality of life is severely compromised in adult patients with atopic dermatitis in Brazil, especially due to mental components. Clinics. 2007;62(3):235-42.

PURPOSE: to measure the quality of life (QoL), either by a specific dermatology or generic self applied questionnaire, in Atopic dermatitis adult Brazilian patients, looking for selected affected groups.

METHODS: We studied the quality of life of 75 Brazilian ambulatory adults with atopic dermatitis using two types of selfanswered instruments: a quality of life generic questionnaire (SF-36) and a 10-item Dermatology Life Quality Index (DLQI) questionnaire. All patients had been treated for at least 6 months, and their disease status was determined by Eczema Area and Severity Index scores.

RESULTS: Quality of life and disease control were found to be related but with low scores both in DLQI $\left(\mathrm{r}^{2}=0.26\right)$ and in SF-36 $\left(\mathrm{r}^{2}=0.20\right)$, but with greater correlation for SF-36 mental components. Using the 75\% percentile distribution of SF36 mean score and the $75 \%$ value of disease severity score, we sorted patients into four groups: I, referring good QoL and mild atopic disease (14/ 75), II, referring bad QoL and with mild atopic disease (19/75), III referring good QoL despite severe atopic disease (5/75) and IV referring bad QoL and severe atopic disease (37/75); all groups presented similar age, education, family income and time of disease progression. There was a higher frequency of women in group II, but without sleep disturbance or increased pruritus, which was present in group IV, with intense itching and sleep disturbances. Analyzing the physical or mental components of the SF36 generic test, discrepant groups II and III presented higher differences related to the mental components of the test, which was also related to DLQI scores, with a similar distribution for the 2 groups and a higher relation to the mental component of the generic test.

CONCLUSION: The quality of life is affected in adult atopic patients, both related to disease severity and also to mental components, but with diverse effects in patient subgroups. Our data show some components that may mask the exact relationship between QoL results and disease severity.

KEY WORDS: Atopic dermatitis; Quality of life; Quality of life questionnaire; Dermatology; Quality questionnaire.

\section{INTRODUCTION}

Atopic dermatitis (AD) is a pruritic, chronic, inflammatory skin condition, with wide-ranging clinical presen-

1-. Dermatology Department, School of Medicine, University of São Paulo 2-. Pathology Dept \& Tropical Medicine Institute - School of Medicine, University of São Paulo/SP, Brazil.

Email: hfandrad@usp.br

Received for publication on August 23, 2006.

Accepted for publication on December, 19, 2006. tation, which affects $2-7 \%$ of the adult population and 10 to $15 \%$ of children ${ }^{1}$. Its prevalence has increased in recent years, doubling each decade ${ }^{2}$. In most individuals the disease begins in infancy but steadily abates throughout childhood, with some patients remaining severely affected throughout their teenage years and adult life $^{3}$, with a resulting impact in adult patient life ${ }^{4}$. This impact of atopic dermatitis in adults is so intense that it affects their quality of life, resulting in a stronger perception of the severity of disease when compared with psoriasis patients ${ }^{5}$. This 
pattern of adult atopic dermatitis leads to psychosocial disturbances in most patients, especially of self-image, and the persistence of the condition may continue to damage patients' self-esteem, their ability to cope with the disease and adherence to therapy ${ }^{6}$. The impact of skin lesions due to visible aspects has huge psychological implications and thus it is strongly advisable for the dermatologist to evaluate the quality of life of the atopic patient ${ }^{7}$. Studies have identified problems such as feelings of shame or embarrassment, anxiety, low confidence and problems with personal, social and work relationships ${ }^{8}$. The assessment of major mood disturbances as anxiety, depression, mood changes, self-esteem or stigmatization were also found in adult $\mathrm{AD}$ patients ${ }^{9,10}$, indicating that the individual response of most patients is related to the disease.

Atopic dermatitis is usually chronic, and its treatment demands a high level of patient compliance ${ }^{11}$. Several of the treatments are not innocuous to the patients, meaning that a careful risk-benefit decision must be made before introducing potentially harmful drugs, such as cyclosporin $\mathrm{A}^{12}$. In the decision-making process, the clinical picture is easily assessed by clearly devised standardized protocols, as the EASI, but other aspects of the patient's life, such as its quality, are not so easily measurable ${ }^{13}$. Most studies reporting evaluation of quality of life in dermatology patients use questionnaire-based tests, as the Dermatology Life Quality Index (DLQI), Psoriasis Disability Index (PDI), UK Sickness Impact Profile (UKSIP) and Eczema Disability Index (EDI) ${ }^{14}$. Most studies show the relationship between disease severity and quality of life but all systems present problems. The most usual problem is the adaptation of a general questionnaire to a skin disease, as in the case of the SF36 test ${ }^{15}$. Specific tests have been developed for skin diseases, such as the DLQI or the VQ-Dermato, but some of them were tailored for specific cultural settings and thus may not be fully suited for other populations ${ }^{16,17}$.

The most usual feature of these tests is the agreement between their measurement of quality of life and the clinical presentation of the disease, but this agreement presents low defined impact, as usually expressed by $\mathrm{r}^{2}$ values lower than 0.5 in most descriptions. The impact of a skin disease on quality of life is usually more significant for the patient than the risk imposed by the disease itself ${ }^{18}$, which could explain the low agreement.

Some events may be responsible for those characteristics and affect evaluation of the response to the questionnaire, which, in turn, must be adequate for evaluating patient evolution or therapy effect, if the improvement of quality of life is being considered as a treatment goal.

We analyzed the quality of life by two questionnairebased instruments administered to adult Brazilian patients with atopic dermatitis, one generic and the other diseaserelated, dissecting their components in those patients, regarding the impact of disease severity in their quality of life, looking for specific factors that could affect this measure.

\section{METHODS}

\section{Sample Population and clinical analysis.}

This study was conducted at the Outpatient Dermatology Clinic which is part of the General Hospital of the School of Medicine of the University of São Paulo (Hospital das Clínicas da Faculdade de Medicina da Universidade de São Paulo), a large, 3200-bed teachingtraining hospital in São Paulo, Brazil. The study was approved by the Institutional Ethics Committee. Patients were diagnosed and treated as isolated atopic dermatitis by the attending clinician, and were sent for interview during their treatment. Each patient was thoroughly informed; those who agreed to participate gave their written consent. Illiterate and $<18$ year old patients were excluded. EASI scores were determined at this time, when each participant answered the DLQI and SF36 questionnaires alone and in a quiet room, without interruptions. The sample was collected between January and July of 2004, with 75 patients with atopic dermatitis diagnosed according to the reported criteria ${ }^{21}$, with demographic and EASI data and complete DLQI and SF36 questionnaires. Disease severity was assessed by Eczema Area and Severity Index (EASI), which involves an assessment of disease extent on a scale of 0 to 6 in 4 defined body regions (head/neck, upper limbs, trunk, lower limbs) plus an evaluation of erythema, infiltration and/or papulation, excoriation, and lichenification, each on a scale of 0 to 3 . The sum of these scores composed the EASI index, which ranged from 0 , or no disease, to 72 , or maximum disease ${ }^{22}$.

Quality of life assessment. Quality of life was evaluated through two questionnaire-based tests: a generic (SF36) and a specific dermatology instrument (DLQI). The Medical Outcomes Study 36- Item Short- Form Health Survey (SF-36) is a self-administered, multidimensional, widely used and well-validated generic instrument. Questions pertain to the individual's typical routine day, the past four weeks and experiences in general. The SF- 36 comprises 36 items, with 1 Physical (PCS-36) and 1 Mental (MCS- 36) Component Summary Score, based on specific 8 domains scores, from 0 to 100 , combined into a physical and mental scale. Alternatively, a mean value of all domains was also used, ranging from 0 , worst, to 100 , the best quality of life. This questionnaire has shown satisfactory reliability and va- 
lidity and has been tested for psychometric properties in several countries, including Brazil ${ }^{23}$.

The Dermatology Life Quality Index (DLQI) is a simple, compact, dermatology-specific test, applicable to patients with any skin disease. It measures how much a skin problem has affected the life of the patient over the previous 7 days: it consists of 10 items, 6 dimensions and 1 overall summary score, and ranges between 0 (the best score) and 30 (the worst score). The 6 dimensions are:1) Symptoms and feelings; 2) Daily activities; 3) Leisure; 4) Work and school; 5) Personal relationships, and 6) Treatment. DLQI is being used in studies of patients with many skin diseases ${ }^{18}$.

Grouping patients according to their referred QoL and disease severity. We sorted patients according to their mean quantitative SF36 value and EASI score. Patients were defined as having a better quality of life when their scores fell into the $25 \%$ highest percentile in the SF 36 mean domain scores distribution of all patients, which is a cut-off value of 80 . Disease severity was also defined using the same rationale, resulting in a cut-off value of 18 for this score; patients were sorted as having a mild disease when their EASI score was lower than 18 and as having a severe disease when EASI was higher than 18. These cut-off values defined four groups: group I with patients with EASI less than 18 and mean SF-36 score over 80, group II with patients with EASI scores lower than 18 and mean SF36 lower than 80, group III with patients with EASI scores over 18 and mean SF-36 score over 80 and group IV with patients with EASI scores over 18 and mean SF-36 score lower than 80.

Statistical analysis. All demographic data were submitted to descriptive statistics for random distribution confirmation. The relation between disease indexes and quality of life indexes were performed using Pearson correlation, expressed by $\mathrm{r}^{2}$ when significant. Sorted groups of patients, using mean SF36 values and EASI scores, were compared for their demographic and clinical data using chi-square test, and DLQI and SF-36 domains quantitative data of sorted groups were compared with ANOVA or KruskalWallis tests, according to variance homegeneity. Data was considered different or significant when the probability of equality was less than $0.05(\mathrm{p}<0.05)$. Data was analyzed using Statistica 4.0 software.

\section{RESULTS}

The demographic data of 75 patients enrolled in the study show the usual gender distribution: $26 / 75(34,6 \%)$ were male and $49 / 75(65,4 \%)$ were female, similar to the usual sex distribution in atopic dermatitis ${ }^{8}$. Age varied from 18 to 53, with a mean of 26 years. Ethnic background was found to be $50 \%$ white, $15 \%$ black and $35 \%$ miscigenated on the basis of patients' self-definitions. The time gap between diagnosis of atopic dermatitis and administration of the quality of life test ranged between 8 months to 50 years, with a mean of 17 years. All patients were middle class urban citizens; $11 \%$ had attended only elementary school, $68 \%$ high school and $21 \%$ had achieved university degree, without bias related to mean family income. Mean scores were: 24.10 (S.D. = 17.7) for EASI, 5.89 (S.D. = 3.06) for itching, and 3.89 (S.D. = 3.72) for insomnia.

Quality of life and disease severity. The distribution of disease severity, expressed as EASI score, and quality of life, measured both by a generic SF-36 test or specific DLQI test, of our patients can be seen in Fig. 1.

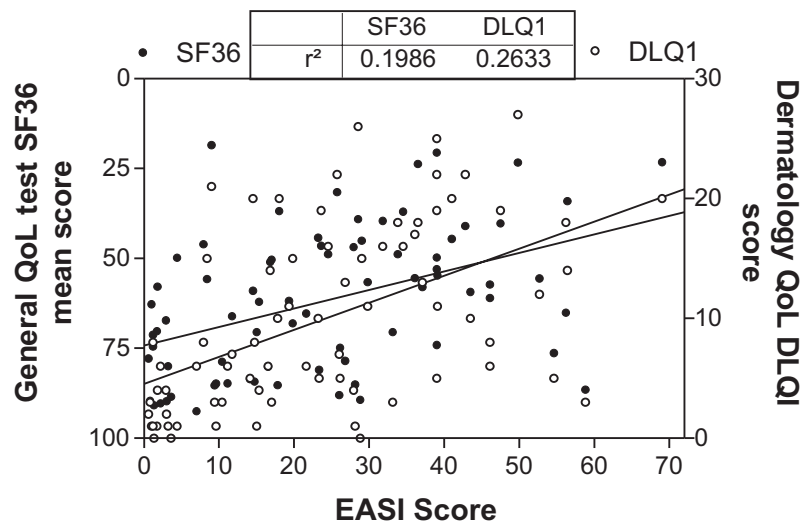

Figure 1 - Distribution of mean scores of Quality of life tests according to disease severity (EASI) in AD adult patients in Brazil. Closed circles: mean value of SF36 domains Open circles DLQI scores. Line shows linear regression of each QoL test. Tables shows correlation between tests and disease severity, both with $\mathrm{p}<0.001$ )

There is a good relationship between QoL and clinical disease severity expressed as EASI in both tests $(\mathrm{p}<0.001)$, slightly better with DLQI test $\left(r^{2}=0,26\right)$ than with mean SF36 $\left(\mathrm{r}^{2}=0,19\right)$, but a large fraction of the patients reported a low QoL, despite mild disease and some patients reported good QoL despite severe skin disease. We analyzed the physical and mental components of the SF-36 test and their relationship with disease severity as can be seen in Fig. 2, showing that the mental component presents lower correlation with disease severity than the physical components, in spite of a higher dispersion of both components in this disease.

Patients were sorted into 4 groups according to their EASI and SF-36 values as specified in Methods (Figure 3). There were 14/75 (18.6\%) concordant patients referring good Qol with mild AD (group I); 19/75 (25.3\%) discord- 


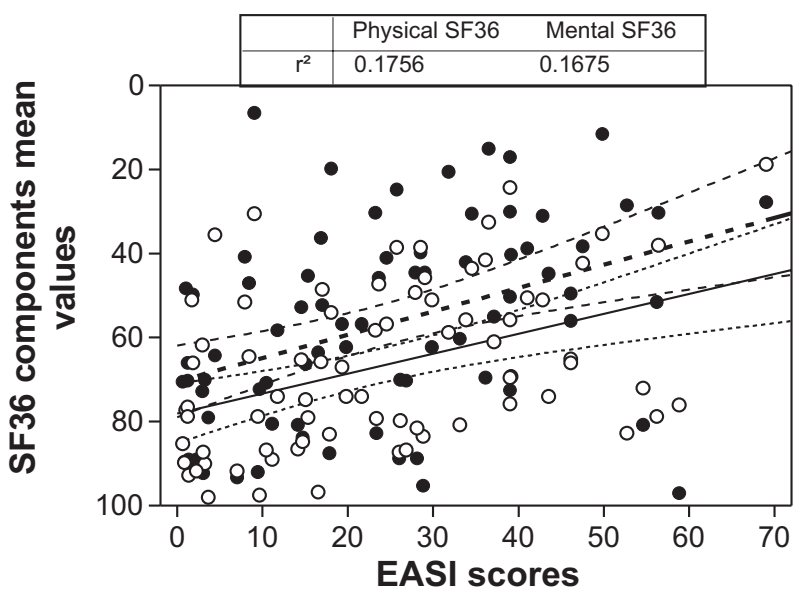

Figure 2 - Distribution and correlation with 95\% intervals of mean values of physical (closed circles and dashed line) and mental (open circles and solid line) components of the SF-36 generic QoL test in AD adults Brazilian patients as related to disease severity, expressed by EASI scores. Table shows values of $\mathrm{r}^{2}$, all data significant $(\mathrm{p}<0.001)$

ant patients referring bad QoL with mild AD (group II); 5/ $75(6.6 \%)$ discordant patients referring good QoL despite severe AD (group III) and 37/75 (49.3\%) concordant patients referring bad QoL with severe AD (group IV).

The distribution according to the specific DLQI test was similar to the sorting with the generic SF-36 (Figure 4), an expected finding as the 2 tests are clearly associated.

All patients were comparable in terms of age, education, family income and time of disease progression, as shown in table 1 . Sex distribution was similar in isolated groups, as shown in Table 1, but group II presented a higher female ratio, as compared with all others groups together $(\mathrm{p}<0.05)$, as shown in Figure 5.

Patient distribution according mental and physical components. We analyzed the physical and mental individual components of SF-36 according to the sorted groups, as shown in Figure 6. The physical component studied, composed by Physical Function, Role-Physical Function, Body pain and General Health perception domains, showed the same pattern of effects on quality of life and disease severity, usually severely affected in group IV as a consequence of disease severity. The mental component, com-

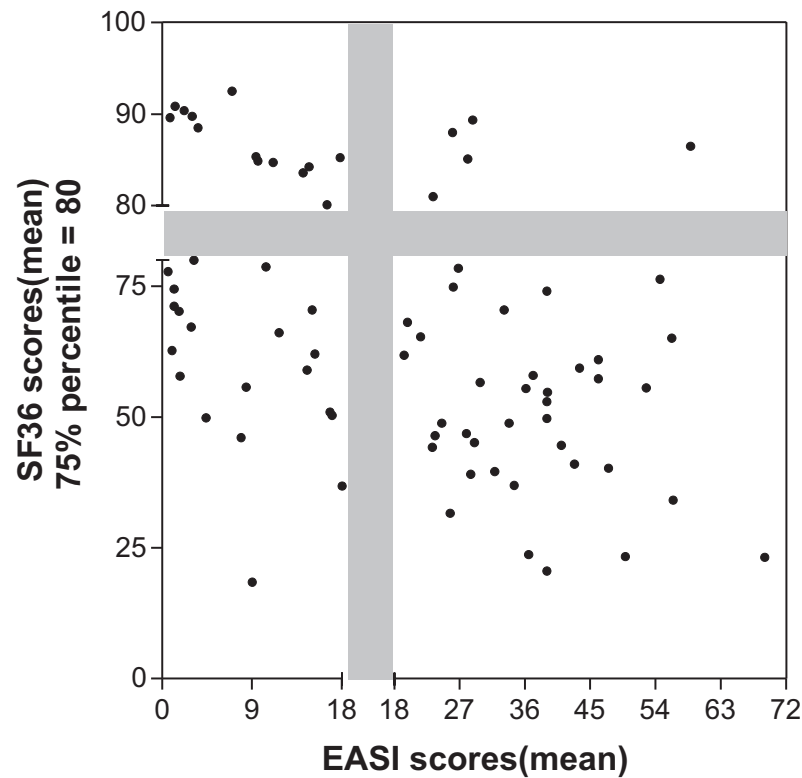

Figure 3 - Selection of subgroups according disease severity, as expressed by EASI scores, and QoL, as expressed by mean domains SF36 values. Dashed areas used for better visualization.

posed by Vitality, Mental Health, Social function, and, especially, Role-Emotional Function domains were most affected and were quite dissimilar between sorted groups, showing a great difference between disease severity and quality of life scores. Regarding the mental component, group II was quite similar to group IV, while group I was similar to group III. The mental component appears to have a great impact on the mean of quality of life scoring.

We also evaluated the scores for some specific symptoms, such as intensity of pruritus and insomnia, and the distribution of those scores in the sorted groups, as shown in Figure 8. Regarding pruritus, the groups presented a broad distribution according to disease severity, group I with lower counts and group IV with higher counts. Sleep disturbances presented a different pattern, with all groups showing a relatively large number of patients without sleep disturbances; however, group III differed from group IV, which showed a large number of patients with sleep disturbances, while patients from group III despite the same disease severity showed less sleep disturbances.

Table 1. Demographic data in AD adult patients, sorted by subgroups

\begin{tabular}{|c|c|c|c|c|c|}
\hline & \multirow{2}{*}{$\begin{array}{c}\text { Total } \\
\text { Sample }\end{array}$} & \multicolumn{4}{|c|}{ Group } \\
\hline & & I & II & III & IV \\
\hline Gender as $\%$ females(females/total) & $65.33(49 / 75)$ & $71.4(4 / 14)$ & $84.21(3 / 19)$ & $60(3 / 5)$ & $54.05(20 / 37$ \\
\hline Age in years $($ mean $\pm S D)$ & $26.28 \pm 8.98$ & $25.64 \pm 8.68$ & $26.80 \pm 10.76$ & $27 \pm 8.15$ & $26.11 \pm 8.53$ \\
\hline Family income(Min. Wage \pm SD) & $6.34 \pm 0.89$ & $5.57 \pm 6.81$ & $6.05 \pm 11.73$ & $5.40 \pm 3.84$ & $6.91 \pm 6$ \\
\hline Education (Semiquantitativescore \pm SD) & $2.57 \pm 0.14$ & $2.14 \pm 0.95$ & $2.42 \pm 1.21$ & $2.00 \pm 0$ & $2.89 \pm 1.28$ \\
\hline Duration of disease (years $\pm \mathrm{SD})$ & $16.74 \pm 1.26$ & $13.2 \pm 8.73$ & $18.57 \pm 14.49$ & $11.80 \pm 9.33$ & $17.78 \pm 9.62$ \\
\hline
\end{tabular}

All groups presents no significant differences with ANOVA test 


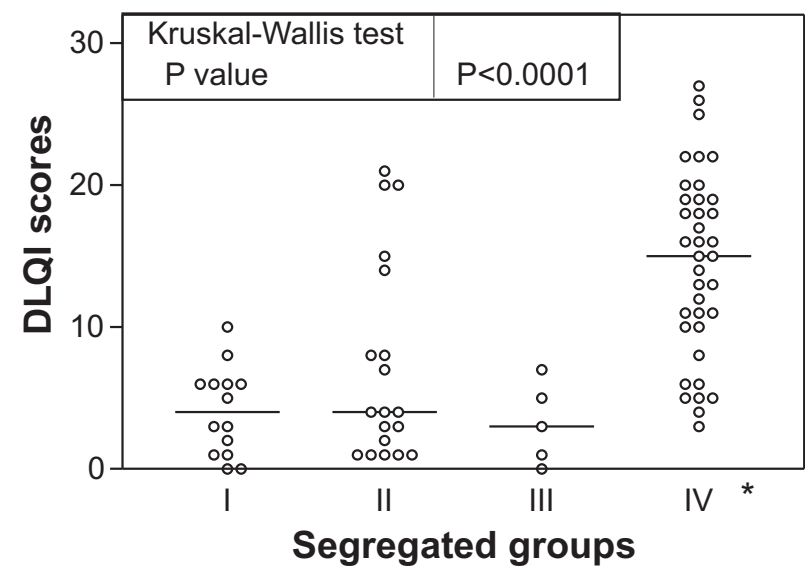

Figure 4 - Quality of life measured by specific dermatological test DLQI, in groups segregated according to methods and fig.3. Bars represent the mean values of each group. Inserted table shows statistical comparison between groups, with $(*)$ marking post-test significance.

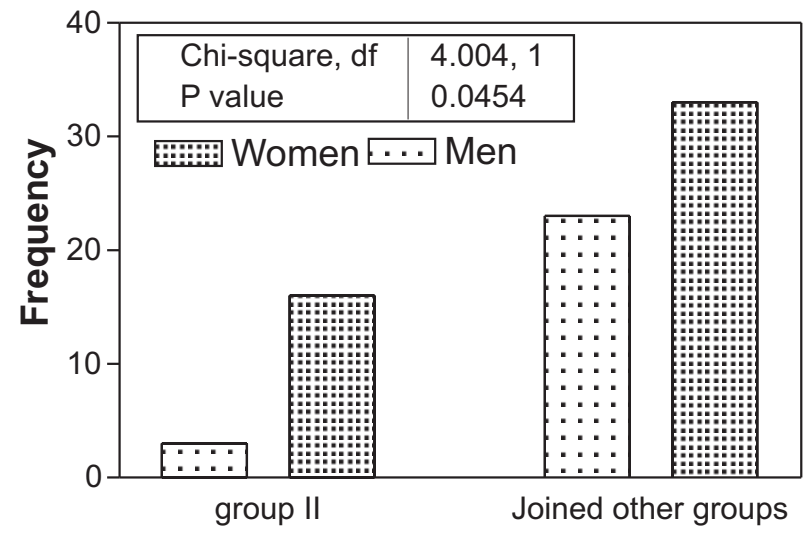

Figure 5 - Female predominance in group II when compared with joined populations of other groups. Table shows Chi-square values and significance.

\section{DISCUSSION}

Our data clearly show that atopic dermatitis in adulthood severely affects QoL of most patients, as described both by a generic test, the SF36, or by a specific dermatology DLQI test. This fact is in agreement with studies comparing atopic dermatitis and other chronic diseases, ${ }^{22}$ apart from the fact that atopic dermatitis has an increasing prevalence in this adult age group II ${ }^{5,26}$. Thus its effects on QoL justifies more aggressive therapies, in order to avoid stigmatization or social problems. Despite the higher costs of aggressive therapy, the resulting improvement in QoL indirectly supports the intervention. Our data in $\mathrm{AD}$ patients are similar to reported QoL analysis in other populations. In those reports, AD patients also presented higher DLQI scores as compared to psoriatic patients, another chronic dermatological affection. Our data suggest that $\mathrm{AD}$ patients present more mental effects of the disease in QoL, as demonstrated by lower scores in social and emotional domains in the SF36 tests, a point also made in other reports ${ }^{11,16,27,28}$. In one of these studies, the DLQI mean score was lower, at 7.3, than in our group, which presented 9.97 as mean value; this was also discrepant from the 5.93 mean value of psoriasis patients ${ }^{27}$. This discrepancy could be attributed to Brazilian cultural aspects; alternatively, it may be due to a more restrictive sample selection in our study, using patients with more severe disease; or a more accurate definition of disease severity, by the EASI score, as the disease severity in the previous study was self evaluated, which could be also affected by mental aspects 27. Another aspect was the younger age of our patients and the longer treatment period, as compared to reported data.
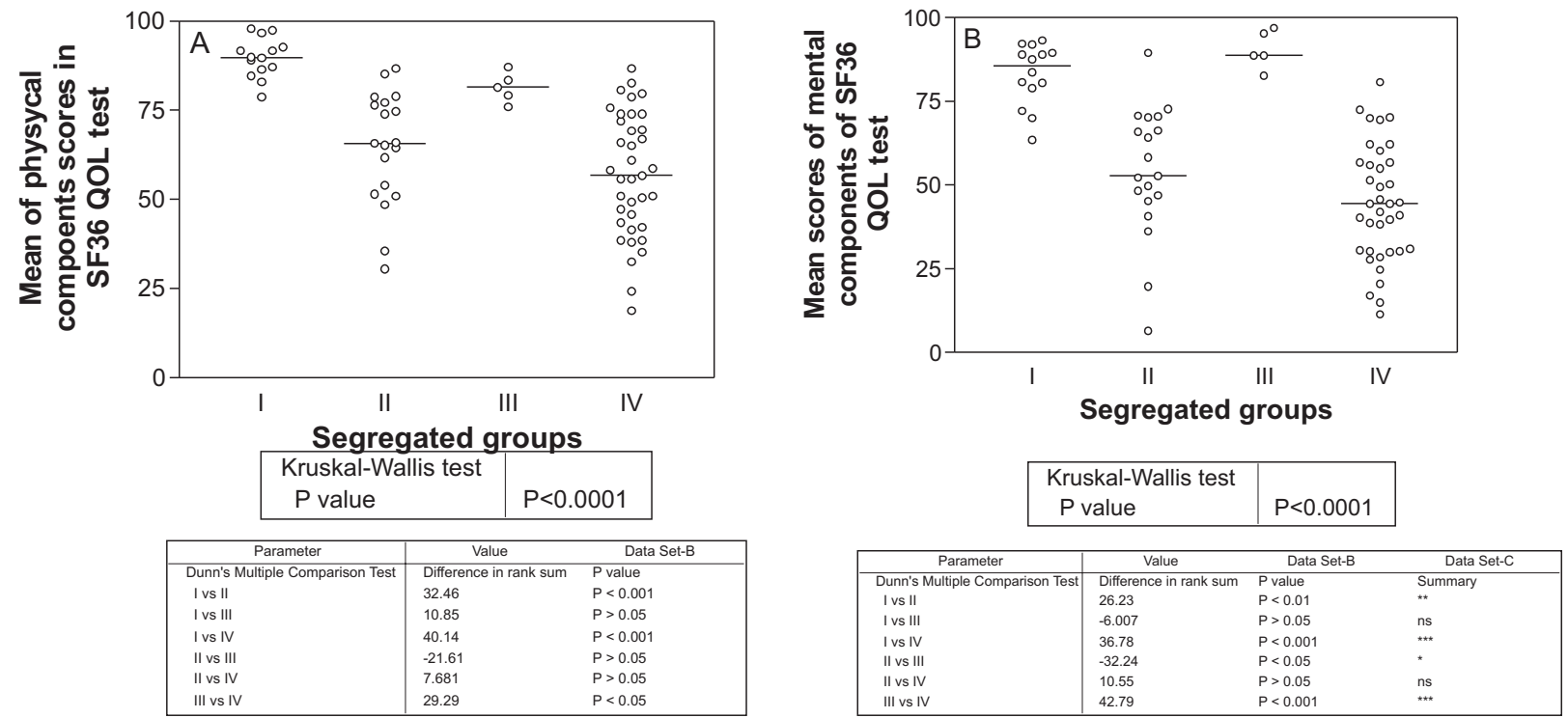

Figure 6 - Distribution of mean values of physical (A) and mental (B) components in the QoL SF36 tests of AD adult Brazilian patients, segregated by groups according methods and fig.3. Table shows analysis of variance and post-hoc comparison (Dunns test) between segregated groups. 
The older population could also be more adapted to $\mathrm{AD}$, due to age or social stabilization, or to the development of coping mechanisms ${ }^{28,29}$. Our data is also similar to a study reporting QoL in psoriasis patients, also analyzed by a Jalowiec Coping Scale and a specific Psoriasis Disability Index (PDI) which showed a crucial mental effect in QoL evaluation. Similar to our findings, the SF-36 mental domains correlated positively to QoL, as opposed to negatively related mental health and $\mathrm{QoL}{ }^{29}$. AD appears to the patient as a restrictive disease, interfering in daily activities, and specially in social and interpersonal relationships, severely impacting emotional aspects of the patients ${ }^{11,12,30}$. This bad QoL effect of $\mathrm{AD}$ was also found when compared to several other dermatological diseases, in a standardization report of DLQI test ${ }^{18}$, also related to disease severity in which the impact of $\mathrm{AD}$ on QoL was higher than other severe dermatological diseases, as psoriasis ${ }^{5}$.

Our study clearly shows that there was general agreement between disease severity and quality of life in the whole sample of atopic dermatitis patients. This agreement was unrelated to the two questionnaires used, SF36 and DLQI, which turned out in very good agreement. This finding was also noted by others, evaluating 239 AD patients, including 107 adults, with worse quality of life, defined by SF-36 and DLQI indexes, related to disease severity ${ }^{25}$. Significant correlation between feeling of stigmatization and disease severity, measured by the Severity Scoring of Atopic dermatitis (SCORAD) was also found more frequently in patients with $\mathrm{AD}$ than with psoriasis ${ }^{10}$. Children with $\mathrm{AD}$ had the quality of life inversely correlated with disease severity evaluated by Children's Dermatology Life Quality Index (CDLQI) and SCORAD, especially in the first visits ${ }^{29}$. The discrepancy of our data in suggesting some specific grouping in the sample was also suggested by others, specially in psoriasis when objective Psoriasis Area Severity Index(PASI) is evaluated, without correla- tion with QoL self assessment ${ }^{32}$. This correlation was attributed to some subgroups present in low numbers in the whole population which affect the main response of the sample. Such hypothesis agrees with the apparent data dispersion in those studies and could also explain several reports that did not find agreement between disease severity and quality of life, as described in studies about the effects of cyclosporin A on atopic dermatitis ${ }^{20}$.

In the present study, we found some subgroups which described their quality of life on the basis of the mental component, leading to patients being described as better QoL in spite of a severe disease or as bad QoL with mild disease. Interestingly, a study investigating the relationship between anxiety and the severity of AD by DLQI using normal hospital staff for comparison, found a correlation between DLQI and severity of $\mathrm{AD}(\mathrm{r}=0.54)$. However, anxiety levels, as scored by STAI, had no relationship with disease severity ${ }^{33}$. The absence of association between medical skin disease evaluation and patient self assessment was also shown during autologous blood therapy in atopic dermatitis ${ }^{34}$. In 51 patients suffering from dermatological disorders, a correlation between physician score and DLQI $(\mathrm{r} 2=0.306)$ was demonstrated, but with differences if the disease was scored by the patient, as expressed by DLQI, or by disease morbidity as scored by the physician ${ }^{35}$. Similarly to our sub-grouping, it was suggested, in the latter study, that patients who are not very sick could overestimate their disease, while more affected dermatological patients underestimated their own disease as compared with their physician. Our findings of gender differences, with women predominance, in group II, was similar to elsewhere reported findings, with females being much more aware and critical to external lesions in atopic disease, as compared to men ${ }^{11,36}$.

Additionally, the analysis of physical and mental components in the SF-36 questionnaires clearly shows that the mental component is the most impacting for scores of qual-
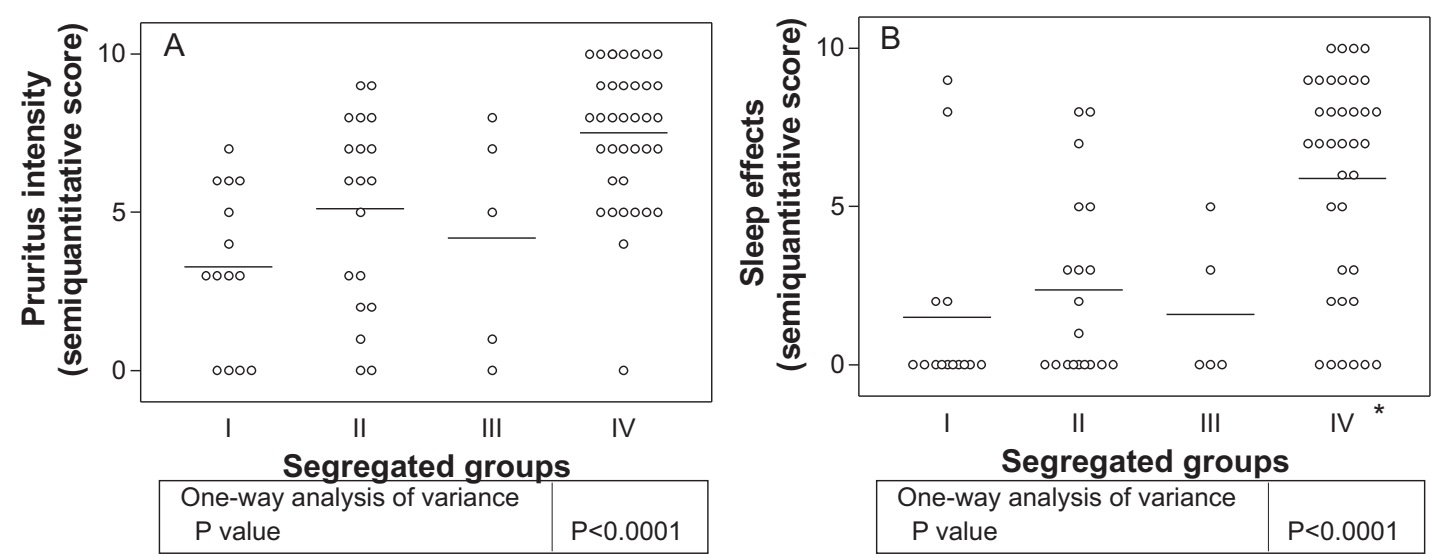

Figure 7 - Major symptoms analysis as pruritus(A) and sleep disturbances(B), evaluated by semiquantative scores as described in Methods, in AD Brazilian adult patients, segregated according methods and fig. 3. Bar represents mean value and table shows ANOVA analysis. $(*)$ marks significant post hoc group. 
ity of life. In view of their higher frequency in our group II of bad QL and mild patients, women are probably more prone to refer bad QoL due to atopic dermatitis, in the presence of a mild disease, a finding also reported elsewhere and which was attributed to self-esteem and related aspects 36,37 . There are also other reports referring to optimistic or pessimistic patients with polarized self evaluation in QoL tests, which could be also more accurately found with our grouping system ${ }^{29}$. When quality of life is assessed, the underlying mental aspects may affect its measure, and we have clearly shown this in our sorted groups. How this bias affects the measurement of quality of life is a matter of debate and newer tests and groups should be tested for elucidation. In fact, we believe that such aspects are inbuilt into any quality of life questionnaire-based test and can- not be easily removed. The solution could be the introduction of filters of those domains which are more emotionally affected, and also quoting their ratio with some physical domains that could measure the optimism or pessimism of each individual patient, correcting QoL for the underlying emotional status of the patient.

Apart from describing the huge effect of $\mathrm{AD}$ in QoL of adult patients, we devised a simple sorting method which allows the discrimination of emotional status and reveals the presence of subgroups in a large sample. We are aware that our proposition as it stands is rather simple and should be improved by choosing a non orthogonal model, but our data has produced promising results. The distinct response of such patients must be studied in order to obtain a correct and unbiased interpretation of their quality of life.

\section{RESUMO}

Coghi S, Bortoletto MC, Sampaio SAP, Andrade Junior HF, Aoki V. A qualidade de vida é muito comprometida em pacientes adultos com dermatite atópica no Brasil, especialmente devido a fatores emocionais. Clinics. 2007;62(3):235-42.

OBJETIVOS: Medir a qualidade de vida (QoL), por questionários tanto genéricos como dermatológicos específicos, em pacientes adultos brasileiros com dermatite atópica, procurando por grupos afetados selecionados.

MÉTODOS: Nós estudamos a qualidade de vida em 75 pacientes brasileiros adultos em tratamento ambulatorial de dermatite atópica, usando dois tipos de questionários de auto-resposta, previamente padronizados: um questionário genérico de qualidade de vida de 36 questões (SF-36) e um questionário de 10 questões para determinação do índice dermatológico de qualidade de vida (DLQI). Todos os pacientes estavam em tratamento por pelo menos seis meses e o seu estágio de doença clinico definido quantitativamente pelo índice padronizado de gravidade e áreas de eczema (EASI).

RESULTADOS: A QoL e o controle da doença estavam relacionados mas com baixa relação tanto avaliados pelo DLQI $\left(r^{2}=0.26\right)$ ou pelo SF-36 $\left(r^{2}=0.20\right)$, mas com maiores relações com os componentes emocionais do SF-36. Usando a distribuição do percentil $75 \%$ para o SF36 e os valores de $75 \%$ do escore de gravidade clínica EASI, os pacientes foram distribuídos em quatro grupos: I que referia boa QoL e doença atópica leve (14/75), II referindo má QoL e doença atópica leve (19/75), III referindo boa QoL apesar de doença atópica mais grave (5/75) e IV concordando uma má QoL referida e uma doença atópica mais grave (37/75); todos os grupos apresentavam mesma distribuição etária, educação e nível social, renda familiar e tempo de doença. Havia uma maior freqüência de mulheres no grupo II, mas sem distúrbios de sono ou prurido intenso, fatores presentes intensamente no grupo IV. Dissecando os componentes físicos e emocionais do SF36, os grupos discrepantes II e II apresentavam maior diferença relativa aos componentes emocionais do teste, que também estavam relacionados aos valores do teste DLQI, o qual apresentava uma distribuição similar entre os grupos e maior relação aos componentes emocionais do teste genérico.

CONCLUSÕES: A qualidade de vida é afetada em pacientes adultos com dermatite atópica, relacionada tanto com a gravidade da doença clinica como com os componentes emocionais, que são diferentes em subgrupos de pacientes. Estes dados mostram componentes que podem mascarar o exato impacto da severidade da doença sobre a qualidade de vida destes pacientes.

UNITERMOS: Dermatite atópica; Dualidade de vida; SF36; DLQI.

\section{REFERENCES}

1. Hanifin J, Saurat JH. Understanding atopic dermatitis: pathophysiology and etiology - Introduction. J Am Acad Dermatol 2001;45(1 Suppl):S1
2. Williams HC. Is the prevalence of atopic dermatitis increasing? Clin Exp Dermatol 1992;17:385-391. 
3. Graham-Brown RA. Atopic dermatitis: Predictions, expectations and outcomes. J Am Acad Dermatol 2001;45(1 Suppl):S61-3.

4. Finlay AY. Measures of the effect of adult severe atopic eczema on quality of life. J Eur Acad DermatolVenereol 1996;7:149-154.

5. Kurwa HA, Finlay AY. Dermatology in-patient management greatly improves life quality. Br J Dermatol 1995;133(4):575-8.

6. Wittkowski A, Richards HL, Griffiths CE, Main CJ. The impact of psychological and clinical factors on quality of life in individuals with atopic dermatitis. J Psychosom Res 2004;57(2):195-200.

7. Halioua B, Beumont MG, Lunel F. Quality of life in dermatology. Int J Dermatol 2000;39(11):801-6.

8. Long CC, Funnell CM, Collard R, Finlay AY. What do members of the National Eczema Society really want? Clin Exp Dermatol 1993;18(6):51622.

9. Ginsburg IH, Prystowsky JH, Kornfeld DS, Wolland H. Role of emotional factors in adults with atopic dermatitis. Int J Dermatol 1993;32(9):656-60.

10. Schmid-Ott G, Kuensebeck HW, Jaeger B, Werfel T, Frahm K, Ruitman $\mathrm{J}$, et al Validity study for the stigmatization experience in atopic dermatitis and psoriatic patients. Acta Derm Venereol 1999;79(6):4437.

11. Holm EA, Wulf HC, Stegmann H, Jemec GBE. Life quality assessment among patients with atopic eczema. Br J Dermatol 2006;154:719-25.

12. Schiffner R, Schiffner-Rohe J, Landthaler M, Stolz W. Treatment of atopic dermatitis and impact on quality of life: a review with emphasis on topical non-corticosteroids. Pharmacoeconomics 2003;21(3):159-79.

13. Czech W. Brautigam M, Weidinger G, Schopf E. A body-weightindependent dosing regimen of cyclosporin microemulsion is effective in severe atopic dermatitis and improves the quality of life. J Am Acad Dermatol 2000;42(4):653-9.

14. Finlay AY. Measurement of disease activity and outcome in atopic dermatitis. Br J Dermatol 1996;135(4):509-15.

15. Finlay AY. Quality of life measurement in dermatology: a practical guide. Br J Dermatol 1997;136(3):305-14.

16. Baron SE, Morris PK, Dye L, Fielding D, Goulden V. The effect of dermatology consultations in secondary care on treatment outcome and quality of life in new adult patients with atopic dermatitis. Br J Dermatol 2006; 154:942-9.

17. McHorney CA, Ware JE Jr, Raczek AE. The MOS 36-Item Short-Form Health Survey (SF-36): II. Psychometric and clinical tests of validity in measuring physical and mental health constructs. Med Care 1993;31(3):247-63.

18. Finlay AY, Khan GK. Dermatology Life Quality Index (DLQI)—a simple practical measure for routine clinical use. Clin Exp Dermatol 1994;19(3):210-6.

19. Grob JJ, Revuz J, Ortonne JP, Auquier P, Lorette G. Comparative study of the impact of chronic urticaria, psoriasis and atopic dermatitis on the quality of life. Br J Dermatol 2005;152(2):289-95.

20. Salek MS, Finlay AY, Luscombe DK, Allen BR, Berth-Jones J, Camp $\mathrm{RD}$, et al. Cyclosporin greatly improves the quality of life of adults with severe atopic dermatitis. A randomized, double-blind, placebocontrolled trial. Br J Dermatol 1993;129(4):422-30.
21. Hanifin JM, Rajka G. Diagnostic features of atopic dermatitis. Acta Derm Venereol 1980;92(suppl):44-47.

22. Hanifin JM, Thurston M, Omoto M, Cherill R, Tofte SJ, Graeber M. The eczema area and severity index (EASI): assessment of reliability in atopic dermatitis. EASI Evaluator Group. Exp Dermatol 2001;10(1):11-8.

23. Cicconeli RM. "Portuguese translation and validation of a generic questionnaire for evaluation of quality of life, "Medical Outcome Study 36-item Short-Form Health Survey (SF-36)".Thesis, Universidade Federal de São Paulo; São Paulo, Brazil, 1997.

24. Kiebert G, Sorensen SV, Revicki D, Fagan SC, Doyle JJ, Cohen J, et al Atopic dermatitis is associated with a decrement in health-related quality of life. Int J Dermatol 2002;41(3):151-8.

25. Lammintausta K, Kalimo K, Raitala R, Forsten Y. Prognosis of atopic dermatitis. A prospective study in early adulthood. Int J Dermatol. 1991;30(8):563-8.

26. Ozkaya E. Adult-onset atopic dermatitis. J.Am Acad.Dermatol.,2004 52(4):579-582.

27. Lundberg L, Johannesson M, Silverdahl M, Hermansson C, Lindberg M. Health-related quality of life in patients with psoriasis and atopic dermatitis measured with SF-36, DLQI and a subjective measure of disease activity. Acta Derm Venereol 2000;80(6):430-4.

28. Lundberg L, Johannesson M, Silverdahl M, Hermansson C, Lindberg M. Quality of Life, health-state utilities and willingness to pay in patients with psoriasis and atopic eczema. Br J Dermatol 1999;141:1067-75.

29. Wahl A, Hanestad BR, Wiklund I, Moum T. Coping and quality of life in patients with psoriasis. Qual Life Res. 1999 Aug;8(5):427-33.

30. Herd RM, Tidman MJ, Ruta DA, Hunter JA. Measurement of quality of life in atopic dermatitis:correlation and validation of two different methods. Br J Dermatol. 1997;136:502-7.

31. Ben-Gashir MA, Seed PT, Hay RJ. Predictors of atopic dermatitis severity over time. J Am Acad Dermatol. 2004 Mar;50(3):349-56.

32. Heydendael VM, de Borgie CA, Spuls PI, Bossuyt PM, Bos JD, de Rie MA. The burden of psoriasis is not determined by disease severity only. J Investig Dermatol Symp Proc. 2004;9(2):131-5.

33. Linnet J, Jemec GB. An assessment of anxiety and dermatology life quality in patients with atopic dermatitis.Br J Dermatol 1999;140(2):268-72.

34. Pittler MH, Armstrong NC, Cox A, Collier PM, Hart A, Ernst E. Randomized, double-blind, placebo-controlled trial of autologous blood therapy for atopic dermatitis.Br J Dermatol 2003;148(2):307-13.

35. Jemec GB, Wulf HC. Patient-physician consensus on quality of life in dermatology. Clin Exp Dermatol 1996;21(3):177-9.

36. Holm EA, Esmann S, Jemec GB.Does visible atopic dermatitis affect quality of life more in women than in men? Gend Med. 2004 Dec;1(2):125-30.

37. Jobanputra R, Bachmann M. The effect of skin diseases on quality of life in patients from different social and ethnic groups in Cape Town, South Africa. Int J Dermatol 2000;39(11):826-31. 